\title{
On the Origin and Features of the Pleasing Function of Language
}

\author{
Bin $\operatorname{Han}^{1,2}$ \\ ${ }^{1}$ Department of English Language Education, Graduate School, Silla University, Busan, 46958, Korea \\ ${ }^{2}$ School of Foreign Languages, Zaozhuang University, Zaozhuang, Shandong, 277160, China
}

\begin{abstract}
The main purpose of verbal activity is to exchange information, and the language used in verbal activity can also realize a pleasing function. According to people's awareness of language's pleasing function in language use, the pleasing function of language can be divided into two types: explicit pleasing function and implicit pleasing function. According to the object of language's pleasing function in verbal activity, it can be divided into three types: others-oriented, self-oriented and twoway pleasing functions. Because language pleasure is connected with the deepest experience of human nature, the use of language satisfies the human needs and realizes the dynamic balance of life, thus realizing the aesthetic pleasure.
\end{abstract}

Keywords-pleasing function of language; explicit; implicit; orient; human needs

\section{INTRODUCTION}

Verbal activities refer to the activities conducted by people using language (including written language and oral language), which is a very important and indispensable behavior and activity in people's life. Verbal activities can be conducted by two or more people in cooperation, such as talking, greeting, exchanging opinions, asking and answering questions, etc. It can also refer to the activities of a single person, such as swearing, cursing, speech, etc.; as in written form, there are news, advertisements, letters and so on. In addition, there are various artistic activities using language, such as singing and calligraphy. The main purpose of verbal activity is to exchange information, but the language used in the activity also realizes a pleasing function.

The fact that language can bring pleasure to its users has attracted many scholars' attention and discussion. Although the recreational function of language is often overlooked, no one will deny the use of language for the hearty joy of using it [1]. Verbal dueling and comic talk are typical examples of using language for amusement. Talking with the other people is actually a means to comfort, liberate, and release oneself psychologically. Therefore, if there are persons who are willing to listen to a speaker, it is really a case of happiness for the speaker [2]. Besides this, Language can also be used just as games, e.g., some of children's songs or nursery rhymes are just for pleasure. Confiding may achieve a speaker's psychological balance. Poetry may transfer one's negative emotion [3].
All the above mentioned cases of language use can bring pleasure to human beings, so the author adopts the term Pleasing Function of Language (PFL) in this article.

People sometimes have a clear awareness of this function and sometimes use it unconsciously. Based on the analysis of related language phenomena, this paper summarizes the types and manifestations of the pleasing function of language and then discusses the origin and anthropological significance of the pleasing function of language.

\section{THE EXPLICIT AND IMPLICIT CLASSIFICATION OF THE PLEASING FUNCTION OF LANGUAGE}

In the author's opinion, according to whether people have a clear awareness of the pleasing function of language in the process of language use, the pleasing function of language can be divided into two types: explicit and implicit.

\section{A. Explicit Pleasing Function of Language}

The explicit pleasing function of language means that the speakers' purpose of pleasing others or themselves by using language are obvious, i.e. both the hearer and the speaker are psychologically aware of this purpose.

\section{1) Verbal language arts}

For example, verbal linguistic forms of entertainment such as jokes, comic crosstalk and comic short plays; these works of art are created by performance artists to entertain the audience. The tool of their creation is language, the object of their creation is language, and the way to present their works is also language. Audiences know this well too, because they go to enjoy jokes, comic crosstalk shows, and comedy shows just for fun. There are other forms of art, such as poetry, singing, calligraphy, etc., which use language to entertain the language user or other audiences or viewers. The rhythm and cadence of the poem are very attractive, and the lyrics of songs are also like poems, which are accompanied by the melody, sometimes high and cheerful, sometimes euphemistic, which makes it catchy and memorable.

\section{2) Calligraphy}

Calligraphy is slightly different from joke and comic crosstalk. It reflects the pleasure brought by the written image of language. Calligraphy belong to the cultural semiotics; it is a cultural product, a good site for the ideology to attach to. It is extremely generative, however, which makes it free from the control of ideology before it is completely occupied by 
ideology [4]. As Yang Lian-sheng, a sinologist at Harvard University, puts it, "One Chinese character is one history." Clodale has also talked about the characteristics of Chinese characters, saying that they contain the Tao of figures and the image of writing [4]. The calligraphy in the East is the writing process with the writing brush appealing in a kind of invisible individual differences, letting a person see the meaning behind it, painting the heart out of vanity through ink. Oriental art is represented by calligraphy; the mixture of its form and significance constitutes the connotation of writing, which transcends the ideological differences not only with the metaphysical discourse power but also relying on a variety of interaction of elements of society, individual, soul, art, and history.

As far as the tangible things of writing are concerned, the words become an incorruptible ideal which is connected with the deepest experience of human nature. This is obvious in Chinese, of which the "writing behavior" has the real power of civilization. As for western phonetic writing, Roland Barthes puts it this way: in recent studies, psychoanalysis has found that words have writing characteristics, even in phonetic writing. The word is the great intersection of symbols (which can be detected from the whole Baroque literature and calligraphy art), and it is the meeting point and starting point of countless metaphors. In the middle ages, the circular script left a treasure house for civilization which is containing experience, dream and meaning. If can be released from the yoke of experience of western society, which reduce and amend the language as a communication tool for innocence, the calligraphy art will be the main art and can be beyond the useless opposite between image and abstraction: every word, all can come to mean something and nothing at the same time, simulating nothing but symbolizing something, however, setting aside the debate between realism and aestheticism [4]. Therefore, the purpose of calligraphy is not the expression of text semantic meaning, but the text structure-the imposing spacial manner created by lines and strokes - which is the overall scenery composed of the direction, intensity, depth and nature by writing the life-will of the subject/writer.

\section{3) New meaning to old words}

Let's have a look at another example. Internet language often gives new meaning to some old words. This is because the assigning of new meanings to old words will bring people the pleasure of innovation, just as if they have created a new word. The following passage from the network is an example.

Popular in each big BBS is a rarely-used Chinese word "yin" (Read with a rising tone). A rarely-used Chinese character can unexpectedly become hot overnight, which implies that the power of the Internet is really very great. After the "jiong” (Read with a falling-rising tone) and "mei" (Read with a rising tone) prevailed, now "yin" is the most popular on the network. For example, "Yin you like killing an ant!", "Yin you immediately!", "Man, what will matter is not being handsome and gentle, is yin!” It is used to describe a person's high morale and boiling blood [5]. The word "yin” just appears on the Internet for a few days, then it is quiet popular in each big BBS, even is popular throughout the Internet.
Language is a dissipative system with its own metabolism, and this is mainly because language is closely linked with the development of human society, as a result, language will change. Like the above example of the Chinese word "yin", a rarely-used word, of which the pronunciation is "yin" with the rising tone, meaning "light". However, being widely circulated on the Internet, the word "yin", which is used to describe a person's high morale and boiling blood, can be used to represent "swagger" or "strong" and many other related meanings. If we traces back, we will find that "yin" originates from the computer or online game players. It is a kind of new cultural phenomenon created by game players. This kind of language creation meets people's language aesthetic requirements to a certain extent. It is the innovation of pronunciation, vocabulary, sentence and discourse that people keep pursuing, which makes language appear in a new and more convenient form. In the process of constantly getting rid of the stale forms and bringing forth the fresh forms of language expression, people also experience the pleasure of creation and aesthetics.

\section{B. Implicit Pleasing Function of Language}

Implicit pleasing function of language refers to the fact that when the contextual atmosphere is unpleasant, some forms of language expression can be used to reduce the speakers' unpleasantness and make them psychologically relaxed and happy. However, when speakers use such language forms, their subjective purpose is not to please themselves, they just objectively achieve the effect of pleasing themselves. Examples include reprimands, insults, subjunctive mood, confiding (pouring out one's feeling), etc. Sometimes it can also be used to entertain others, such as listening to others' talk or singing of their thoughts.

\section{1) Reprimands and insults}

Let's start the discussion about reprimands and insults. When someone is reprimanding and insulting others, they are usually in a bad mood. Speakers can use these forms of language to express and vent their anger. For example, when Chinese people say "tong chi” (denounce scathingly, reproach abusively) and "yi tu wei kuai” (get it off one's chest) and so on, the characters "tong" and "kuai" means that the negative emotions is released through the verbal behavior of reprimanding, i.e. the person's mood will tend to become calm or change to a more positive direction. This objectively reduces the displeasure of the speaker. The measurements from displeasure to pleasure is a kind of ascension, although the speaker is not happy at the very moment of using the language to rebuke or insult, his displeasure has already been reduced, or even eliminated, therefore, rebuke and insult belong to invisible realization of the pleasing function of language, which is implicit. Of course, the realization of this implicit pleasing function of language has a premise that the speaker, to some extent, should have a good self-control over his emotion and can prevent his anger from getting stronger and will not behave unreasonably.

Cognitive psychology research indicates that emotion is a unit or node of semantic network and language to express the semantic concepts can activate semantic node in the network, which will change people's emotions, including both the 
speaker and the hearer [6]. Because people tend to be positive and cheerful, they will seek expression that can achieve relevant functions. To this end, some people even deliberately swear or insult others to entertain themselves with linguistic expressions; the purpose of this pleasure-seeking function is very obvious, although it brings pains to the insulted people. From the moral point of view of public opinion, this is an undesirable, unbeautiful and unencouraged linguistic behavior, but we cannot deny the existence of this phenomenon. Because its pleasure-seeking purpose is very obvious, the author thinks that this kind of linguistic behavior should be the realization of explicit PFL.

\section{2) Subjunctive mood}

Now let's look at subjunctive mood. This is a common language phenomenon, which is used to represent people's hypothesis of what had not happened in the past or at present; it is mainly expressed by means of the unreal conditional adverbial clauses, which indicates what is contrary to fact or what seems unlikely to happen. What is discussed here is mainly the subjunctive mood used to express a kind of regret. The speaker tries to vividly express a lesson. For example: "Hadn't it not been for the expense, I should have gone to Italy." "If he had taken his doctor's advice, he might not have died." People use such language to express a mental picture of a scene or behavior that actually didn't happen in the past but the speaker hopes has already happened. As mentioned above, emotion is a unit or node in the semantic network, and the semantic concepts in language expression will activate the nodes in this network, thus changing people's emotions. So people use subjunctive mood to activate those concept nodes representing the scene and behavior conforming to their desire, as if they can turn the time back in the world of their imagination, to build a virtual success and to get a temporary satisfaction.

\section{3) Confiding}

Now let's discuss confiding - the talk or the linguistic pouring out of one's feeling, such as the words and songs to express the feeling of missing a lover or a relative. For example, in ancient times, it is hard to contact distant relatives, in order to express the feeling of missing one's relatives, people tend to compose poetry or songs and make them rhythmic so it is easy for themselves or the audience to enjoy themselves, to learn the songs and to remember the poetry. Being away from relatives and unable to meet them is a painful experience in one's life, but the language arts as verses of missing give people a kind of aesthetic feeling; although it is a little sad and sorrowful, it can make people perceive more clearly the rich connotation of life and precious human feelings such as affection, romance, and friendship. Language can beautify people's experience, encounter, emotion. After this beautification those things that cannot be beard become tolerable to some extent. Aesthetic feeling will bring psychological pleasure, although accompanied by strong or weak lovesickness and grief of separation. It is precisely because this light sadness which seems containing an implicit joyfulness from the sadness, the author believes that talking/pouring out of one's feeling should belong to the realization of the implicit pleasing function of language. Because in the direct observation of their own language products, people will find their own forces (ideal, emotion, interest) implanted (i.e. the people's essential forces are objectified) and consequently produce a cheerful feeling. People's having aesthetic ideals is also one of the essential human forces [7]. It is certainly that speech acts in accord with or reflecting this essential force will be appreciated and enjoyed, but sometimes in an implicit manner.

\section{THE DIRECTIONS OF THE PLEASING FUNCTION OF LANGUAGE}

According to the objects of pleasing in the process of people's language use, the pleasing function of language (PFL) can be divided into two types. One is others-oriented PFL, the other is self-oriented PFL. Sometimes language uses have twoway pleasing function, that is, realizing both the othersoriented PFL and self-oriented PFL at the same time.

Language can be used to entertain others and to achieve the others-oriented PFL. For example, jokes, comic crosstalk, comic short play and other artistic behaviors related to languages are intended to entertain or amuse the audience. Language can also be used to cheer the users themselves up and achieve the self-oriented PFL. Such as singing, composing poetry, calligraphy, scolding, insulting, subjunctive mood (mainly refers to the virtual/unreal conditional clauses expressing regret, when the speaker tries to vividly express a lesson). And some language activities, such as calligraphy, poetry, singing, talking, etc., can be two-way PFL, because in these activities, in addition to language users, other people such as the audience, the partner, the viewer, or the addressee can also feel the pleasure of language.

Confiding, such as a woman's song of missing her lover, can have a variety of directions of pleasure. Back to what happened in the past, it was the woman who had developed the emotion of missing her husband and added more elements to this feeling because she had enough time. For example, while a woman is spinning gradually alone, she expressed tranquility and loss in her tune accompanied by the spindle's dull hum which sounds so distant, with travel-stained rhythm as the surge of the sea or the rattles of cars [4]. Here the language plays a psychological role in the release of the the woman's depression. This song of missing has a kind of implicit, selforiented PFL. But if the song is heard by other people, and then sung by them and heard by other people again, it will be an explicit, others-oriented, or two-way PFL.

Roland Barthes points out that if you want someone to know something, you have to say it; and at the same time, as long as it's spoken, it's probably be taken as true. This "open heart" - saying or speaking about one's inner world — can solve the only thing that Freud was suffering from and the most terrible thing in Gide's heart-the inability to prove his love to his lover [4]. This kind of linguistic behavior that can relieve pain and eliminate fear should be a manifestation of the pleasing function of language.

As a means for the release and vent of the speaker's emotion, this kind of saying or speaking is exerting the implicit, self-oriented pleasing function of language. Furthermore, If the listener is willing to listen to this kind of "open heart" of saying or speaking about one's inner world, then this verbal activity also realizes the explicit, others-oriented pleasing function of language. 


\section{THE ORIGIN OF THE PLEASING FUNCTION OF LANGUAGE}

Where is the origin of language pleasure? Why can human produce happy psychological state? How does the use of language trigger this pleasure mechanism?

Language pleasure is connected with the deepest experience of human nature. To human beings, the continual development of language is as natural as his inherent nature. In the active and varied life, in the constant struggle against difficulties and needs, and in the constant renewal of the knowledge of things and images, human beings improve themselves and their languages. In discussing the origin of language, Herder said that even the lonely savages in the forest must invent language for themselves, even if they never speak. It was a pact between him and his heart, a kind of agreement as if man could only be man. The older and more primitive the language is, the more intertwined the human feelings become in the root of the word [8]! Because humans use the whole body organs (psychosomatic organs) to perceive the whole world. No matter what state the world is, or no matter how the world forms, each human feeling organ will classify it into all kinds of symbol systems that are perceivable and acceptable for people to receive, and then to realize the cognitive process of human brain by a synthetic analysis such as the various information forms and information contents loaded in body senses, such as taste, touch, perception, and olfactory symbol system. In this way, we can realize the cognitive process of the outside world through the information content provided by these nonverbal symbol systems and keep its cognitive achievements, so as to make the world a part of our internal world. However, Because these symbols have no expressive function, so language symbols have their unique value, i.e. the value of cognitive power and the value to express all human understanding. Despite that this kind of expression inevitably subject to the limitation of language itself, and no matter how deficient the converted content is, the necessity of human communication and information exchange will make those cognitive content loaded in the nonverbal symbol systems be expressed in the language symbols inevitably [9].

Mankind is experiencing the pleasure of success by constantly breaking through the limitation of language symbols. If one opens the oldest and the best oriental language dictionary, a strong desire of self-expression will come pouring in! The original inventor of language must separate ideas forcibly from a kind of feeling, and pass it to another kind of feeling, and the specially slow, clear, or indifferent senses are the main sources of ideas. He must use all his senses and sounds, so as to generate expression! So, in a word root appears the bold and powerful metaphor, and meaning transfer happen from one kind of feeling to another kind of feeling: the meaning of a stem and its derivations will cross or contrast with each other, even form a gorgeous colored picture. This kind of phenomenon is caused by the poorness of human psyche and lies in the convergence of various kinds of perception of primitive people. Primitive people's need of selfexpression is very obvious, and the more the ideas can't be grasped by feeling and sound, the more intense the need of self expression becomes. With this in mind, people have no reason to doubt the human origin of language.
However, people's desire will not reach an absolute balance, and the pursuit of pleasure and happiness is an endless process. This pursuit reflected in language use is a never-ending pursuit of creation, and the result of it is the pronunciation, vocabulary, sentence and discourse which relatively, to a certain extent, meet the aesthetic requirements, so that it can be expressed in more smart and elegant forms. This tendency to seek new creation in language is the living expression of the dynamic balance of human psychology. Aesthetic pleasure comes from the self-discovery of life. As long as anything presents the expression of life, as long as we see the dynamic balance of life in it, we can create aesthetic pleasure.

Moreover, human beings can feel pleased because their needs are satisfied. The scale of human needs includes both practical and aesthetic dimensions. Therefore, people shape objects according to the law of beauty as well as the law of practicality [10]. Naturally, language, the most convenient, practical, handy, and thoroughly personal tool, is also created on a practical scale and on a beautiful scale. As the above mentioned, when people find their own language products are implanted with their own forces like strength, ideal, emotion, and interest, they will feel cheerful. People's having aesthetic ideals is also one of the human essential forces. It is certainly that such speech acts in accord with or reflecting this essential force will be appreciated [7]. Language system does not reject the aesthetic intention of people but embraces it, because they are both dynamically balanced structures, so they fit into each other.

Humboldt believes that among various kinds of human abilities, voice is suited to express his inner feelings best, because the voice of people is as their breath, which is full of vitality and passion. The four important phonetic features of speed, pause, rhythm and intonation are not natural products of human vocal organs but consciously controlled by the state of life. Language in use should be practical first, and then be beautiful to view, to listen and to read [11]. The elegant and polite language use can meet the requirements of the above two scales of course, but even rude words, such as quarreling and cursing, are both practical and beautiful in the mind of the language users at the very moment of using the language. Many kinds of human language art forms, such as singing, reciting, opera, etc., rely on these phonetic features to achieve their artistic appeal and delight the audience or the performers themselves.

Now let's discuss an example about speech and voice. According to Quine, the general rule for the society to teach a person to use the word "Ouch" is as following: when a person is seen showing suddenly the frowning expression of feeling unwell or suffering from violence, he will be encouraged to shout "Ouch"; Otherwise, if he has not been touched at all, or if his facial expression remains peaceful, but he cries out "Ouch”, he shall be punished [12].

People will say "Ouch" when they feel painful. Is this action of saying/shouting just a conditional reflection? Does crying out in pain relieve pain? And if it does, it increases the speaker's pleasure in a certain sense, although in an implicit way. Can this phenomenon be classified as the pleasing function of language? Perhaps some people think that it 
depends on whether the content being shouted is a linguistic expression. But even if the shout is not a standard linguistic expression, it can be described in linguistic specification. If it's not a standard linguistic expression, why do we say that the person is shouting "Ouch" instead of "Aha”? This analysis is from the point of view of a narrator other than the experiencer. Even from the shouter's point of view, he himself will also describe that he has just shouted "Ouch!”.

In this case, the external sounds of a word has nothing to do with our analysis. We mean the internal and necessary occurrence of a word, which is a clear sign of conscious action. Bakhtin once proposed that all ideology is a symbol, and this symbol belongs to a "material part" or "material intermediary" of reality. No matter what the meaning of a word is, it creates a connection between individuals in a social environment of a certain breadth, which is objectively reflected in the collective reactions of people [13]. These conventional linguistic expressions in people's consciousness also show that language is a social phenomenon.

Language is not a purely physical and psychological phenomenon, but an expressive act. It's not just individual expressive behavior, but social expressive behavior. It is not a purely subjective or unconscious expression, but an active response to social stimuli in social and environmental conditions. In short, language, as a linguistic response, is the actual expressive behavior of people formed in the natural and social environment [14]. In other words, language is a basic skill and function of human beings, as a result, the normal use of language will give human beings pleasure.

\section{CONCLUSION}

Language, as a kind of developing, moving, changing, rising and declining life activity, has its inner energy transformation mechanism and an independent system exchanging information with the environment, and language itself is also an open system full of vigor and vitality-an "ecosystem".

Language is not only an important tool for human communication and thinking, but also a mirror of people's psychological activities. There is no denying the fact that people use language to express ideas, feelings, and experiences; in this process, language sometimes is achieving its pleasing function: language is like a natural part of our body functions. People purposefully or inadvertently use this function. Language communication and expression can bring pleasure to people's mental and psychological state.
Language can relieve people's psychological pressure, produce good mood, wake up the sleeping soul, release the potential of the spirit, raise our creativity, or refresh our aesthetic consciousness and ability. The pleasing function of language is the conjunction, harmony and resonance of two kinds of dynamic balance structure - the human physical and psychological dynamic balance structure and the language dynamic balance structure. Language pleasure is a part of the harmonious effect of life. Different forms of the pleasing function of language respectively evoke the various states of life. Of course, there are many factors which can affect the language use system, so, the pleasing function of language remains to be further studied from different perspectives.

\section{REFERENCES}

[1] Zhuang-lin Hu, Linguistics: A Course Book, 5th ed. Beijing: Peking University Press, 2015.

[2] Qiu-yue Han, Confiding and Leaking. Happiness. 2009(23), p60.

[3] Meng Wang, Functions and Pitfalls of Language. Journal of Ocean University of China (Social Sciences Edition), 2004(06), pp. 57-64.

[4] R. Barthes, Fragments d'un Discours Amoureux. Paris: Seuil, 1977. Transl. Wang Yaojin, Wu Peirong. In Chinese. Shanghai: Shanghai People's Publishing House, 2004.

[5] https://news.qq.com/a/20090916/001216.htm

[6] G.H. Bower, \& S.G. Gilligan, “Cognitive consequences of emotional arousal” in C. Izard, J. Kagen, \& R. Zajonc, Eds. Emotions, Cognition, and Behaviour. New York: Cambridge University Press, 1984, pp. 547588.

[7] Guan-lian Qian, Aesthetic Linguistics, Language and Speech. In Chinese. Shenzhen: Haitian Publishing House, 1993.

[8] J.G. Herder, Abhandlung uber den Ursprung der Sprache. Berlin: Christian Friedrich Voß, 1772. Transl. Xiao-pin Yao, In Chinese. Beijing: The Commercial Press, 1998.

[9] Bao-yu Han, Language and Human Meaning World. In Chinese. Beijing: China Social Sciences Press, 2002.

[10] Shi-de Wang, Aesthetics. In Chinese. Jinan: Shandong Literature and Art Publishing House, 1987.

[11] W.H. Humboldt, Collection of Humboldt's Essays on Linguistic Philosophy. Transl. Xiao-ping Yao, In Chinese. Beijing: The Commercial Press, 2011.

[12] W.V.O. Quine, Word and Object. New York: John Wiley \& Sons, Inc., and The Technology Press of the Massachusetts Institute of Technology, 1960. Transl. Qi-wei Chen, Zhu Rui, Xue-guang zhang, In Chinese. Beijing: China Renmin University Press, 2005.

[13] Yi-chuan Wang, Utopia in Language: an Exploration of Western Linguistic Aesthetics in the Twentieth Century. In Chinese. Kunming: Yunnan People's Publishing House, 1994.

[14] V. N. Volosinov (M. M. Bakhtin), I.R. Titunik, N.H. Bruss, Freudianism: A Marxist Critique. unpublished. 1927. In Chinese. Beijing: China Literary Federation Press, 1987. 